\title{
The relationship between irritable bowel syndrome and psychiatric disorders: from molecular changes to clinical manifestations
}

\author{
Mihaela Fadgyas-Stanculete ${ }^{1}$, Ana-Maria Buga ${ }^{2}$, Aurel Popa-Wagner ${ }^{2,4}$ and Dan L Dumitrascu ${ }^{3 *}$
}

\begin{abstract}
Irritable bowel syndrome (IBS) is a functional syndrome characterized by chronic abdominal pain accompanied by altered bowel habits. Although generally considered a functional disorder, there is now substantial evidence that IBS is associated with a poor quality of life and significant negative impact on work and social domains. Neuroimaging studies documented changes in the prefrontal cortex, ventro-lateral and posterior parietal cortex and thalami, and implicate alteration of brain circuits involved in attention, emotion and pain modulation. Emerging data reveals the interaction between psychiatric disorders including generalized anxiety disorder, panic disorder, major depressive disorder, bipolar disorder, and schizophrenia and IBS, which suggests that this association should not be ignored when developing strategies for screening and treatment. Psychological, social and genetic factors appear to be important in the development of IBS symptomatology through several mechanisms: alteration of HPA axis modulation, enhanced perception of visceral stimuli or psychological vulnerability. Elucidating the molecular mechanisms of IBS with or without psychiatric comorbidities is crucial for elucidating the pathophysiology and for the identification of new therapeutical targets in IBS.
\end{abstract}

Keywords: Irritable bowel syndrome, Psychiatric disorders, Comorbidities, Brain-gut axis, Psychosocial factors

\section{Review}

\section{Introduction}

Irritable bowel syndrome (IBS) is a functional syndrome characterized by chronic abdominal pain accompanied by altered bowel habits $[1,2]$. IBS is a painful condition associated with significant psychological distress and psychiatric comorbidities, like higher levels of anxiety or depression and suicidal ideation, with negative impact on quality of life [2,3]. Its consequences are measured in direct cost (medical treatment and procedures) and indirect cost (reduced productivity) [4].

The Rome committee published in 1992 the first clinical diagnostic criteria of IBS that could be also used in research. The latest version, Roma III diagnostic criteria, are the current golden standard for diagnosing IBS patients. According to these criteria, IBS is defined as recurrent abdominal pain or discomfort at least 3 days/

\footnotetext{
* Correspondence: ddumitrascu@umfcluj.ro

${ }^{3}$ 2nd Department of Medicine, Iuliu Hatieganu University of Medicine and Pharmacy, Cluj-Napoca, Romania

Full list of author information is available at the end of the article
}

month in the last 3 months associated with two or more of the following: a) improvement with defecation, b) onset associated with a change in the frequency of stool, c) onset associated with a change in form (appearance) of stool. IBS can be subtyped into categories based on the main bowel habit: IBS with constipation (IBS-C), IBS with diarrhea (IBS-D), mixed IBS (IBS-M), and unsubtyped IBS (IBS-U) [5].

Depending on diagnostic criteria used (Manning, Rome I, Rome II, Rome III), IBS is estimated to affect approximately $11 \%$ of the global population. A recent meta-analysis shows the lowest occurrence in South Asia (7\%) and the highest in South America (21\%) [6]. IBS is reported more frequently by women than men in Western countries, female-male odd ratio being 2:1 and seems to be more common in the ages between 20 and 40. Based on different symptoms observed, the researchers speculated that sex hormones may alter the regulatory mechanisms of the brain-gut-microbiota axis involved in the pathophysiology of IBS [7].

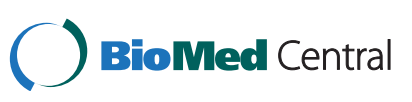

(c) 2014 Fadgyas-Stanculete et al.; licensee BioMed Central Ltd. This is an Open Access article distributed under the terms of the Creative Commons Attribution License (http://creativecommons.org/licenses/by/4.0), which permits unrestricted use, distribution, and reproduction in any medium, provided the original work is properly credited. The Creative Commons Public Domain Dedication waiver (http://creativecommons.org/publicdomain/zero/1.0/) applies to the data made available in this article, unless otherwise stated. 
The etiology of this syndrome is multi-factorial and has been attributed to dysregulation of the brain-gut axis, HPA axis, altered gastrointestinal motility, visceral hypersensitivity, infectious factors, enhanced immunological reactivity, genetic susceptibility and psychosocial factors. Communication between central nervous system and enteric nervous system implies a bidirectional connection system: the brain influences the function of the enteric nervous system, and the gut influences the brain via vagal and sympathetic afferents. The symptoms may be caused by dysfunctions either primarily in the central nervous system, or in the gut, or by a combination of both [8-11].

Stress often worsens the symptoms of patients with IBS. Hypothalamic-pituitary-adrenal axis (HPA axis) is an important component of regulatory mechanisms governing behavioural, neuroendocrine and autonomic responses to stress. The hypothalamic-pituitary-adrenal (HPA) axis and the sympathetic nervous system (SNS) are the two major branches of this central stress response system. Hyperactivation of this pathway may be involved in IBS pathophysiology. For example, a hyperreactive responce of the brain and gut to corticotropin-releasing hormone $(\mathrm{CRH})$ and alterations in adrenocorticotropin hormone $(\mathrm{ACTH})$ and cortisol, and catecholamine levels have been reported in IBS patients [12-14]. Indeed, peripheral administration of CRH improved colonic function and visceral perception in response to gut stimulation in IBS patients [13]. In addition, previous studies showed that the IBS is associated with significantly lower vagal tone and increased sympathetic activity [14]. Therefore it has been proposed that the interaction between different factors like brain-gut axis, HPA axis and inflammatory response can exacerbate IBS symptoms and therefore may play an important role in IBS etiology [9].

Gastrointestinal symptoms have been recognized to occur in relation to fear, anxiety and stress. The gut motility has been found to be reactive to changes in the emotional state. Also, stress has been showed to affect both motility and visceral hypersensitivity. Over the past several years, a great deal of research has evaluated the relationship between IBS and psychiatric disorders. Rates of co-morbidity with psychiatric disorders range from 54 to $94 \%$ in treatment-seeking patient with IBS [15-17].

Psychiatric disorders and IBS appear to have bidirectional co-morbidities. The frequency and severity of the symptomatology of IBS in patients with anxiety and mood disorders have been well documented. Evolution of IBS symptoms seems to be influenced by affective factors and psychosocial stressors $[2,18]$. Those factors may contribute to predisposition, precipitation and maintenance of IBS symptoms, and they also influence the clinical outcome $[3,19]$. Psychiatric interventions (pharmacologic or psychotherapy) have proved effectiveness in the improvement of IBS patient functioning.
In this review, we emphasize the relationship between IBS and psychiatric disorders.

\section{Brain imaging studies}

Patients with IBS also exhibit differences in brain morphology, when compared with healthy volunteers. IBS patients showed association of disease onset with thicker right posterior insula, but the association with psychological symptoms was not proved [20]. The results of another study support the hypothesis that IBS patients with chronic pain exhibit long-term microstructural changes within the brain, particularly in cortical regions associated with integration of sensorial information and corticothalamic modulation [21]. For example, patients with IBS also showed increased hypothalamic gray matter [22,23] that may be related to pain-related overstimulation of the hypothalamic-pituitary-adrenal axis. Likewise, IBS was associated with decreased gray matter density (GMD) in different regions of the brain (medial prefrontal cortex, ventro-lateral prefrontal and posterior parietal cortex, ventral striatum, and thalami) [24]. Changes in the density of gray matter among regions involved in cognitive functions are specifically observed in patients with IBS, albeit different levels of anxiety and depression can explain changes in other areas of the brain. The findings of another study on a sample of female IBS patients with moderate symptom severity suggest that morphometric alterations occur primarily in brain networks involved in attention and emotion modulation, as well as in pain modulatory networks, and in systems processing interoceptive information [22].

Changes in gray matter volume and cortical thickness (CT) have been demonstrated in subjects with IBS, especially in female IBS $[16,25]$. Also, compared with healthy subjects, in IBS patients, the right part of cingulate gyrus and thalamus are critical for information flow. Brain areas involved in pain modulation were identified as network hubs in IBS $[23,26]$.

About 15 years ago, functional brain imaging was introduced as a novel method to examine the interactions between gut and brain. The technique has provided the opportunity to assess the neurobiological substrates involved in human behavior and visceral homeostasis. Recent studies in neuroscience have shown that the brain functions involved in emotion are modulated by visceral pain. The researchers identified two important neural networks with abnormal functioning: the lateral prefrontal regions of the descending pain inhibition network, and the emotion-arousal networks. Furthermore functional imaging studies may provide relevant information about cognitive mechanisms, which may be involved in neurobiological abnormalities of IBS $[27,28]$.

Functional MRI (fMRI) studies point to dysfunction of emotion and attention processing of pain in IBS. Patients 
with IBS pain can be verbally programmed to produce placebo analgesia by decreased brain activity related to cerebral mechanisms involved in memory and semantic processing [29]. Since then, an increasing number of imaging studies assessed the brain activity in regions involved in processing the visceral homeostatic afferent input and have shown abnormal activity in different regions of the brain (anterior/mid cingulate cortex primary and secondary somatosensory cortex, insular cortex, thalamic and prefrontal cortex).

The affective component of physical pain is processed cortically by the dorsal anterior cingulate cortex and the anterior insula. Both regions have some of the highest numbers of mu-opioid receptors in the central nervous system [30]. The perception of pain is modulated by several factors like affective and sensory aspects of the painful stimulus, coping strategies and personality features [31,32]. Catastrophic thinking increases the frequency of maladaptive thoughts about pain and neuroticism is correlated with increased sensitivity to negative cues.

A quantitative meta-analysis of available data revealed that patients with IBS appears to show greater activation of amygdale and perigenual anterior cingulate gyrus nodes, but similar activation of regions involved in the processing of visceral afferent information, as compared with healthy controls [32]. Further, patients with IBS have increased activity in the insula and decreased activation of the dorsolateral prefrontal cortex in response to visceral stimulation [33,34].

One recent study investigated if the patients have impairments in cognitive flexibility due to dysfunction in the dorsolateral prefrontal cortex and insula, and altered connectivity between brain regions. Event-related fMRI of the brain was performed to evaluate cognitive flexibility and was assessed by the Wisconsin Card Sorting Test (WCST). The subjects with IBS presented significantly more perseverative errors, and set-maintenance difficulties than controls. The results showed significantly increased activity of the left posterior insula at error feedback during set-shifting, and significantly decreased activity of the right dorsolateral prefrontal cortex, and right hippocampus in subjects with IBS [34].

Some other studies showed that in IBS, rectal distention determine anterior cingulate cortex (ACC) activation that correlates with anxiety, maladaptive coping, stressful events and a history of abuse. IBS diagnosis and abuse history appear to have synergistic effects causing even greater activation of the perigenual pACC. These studies support clinical observations regarding the connections between psychological distress, IBS, and increased pain [35].

\section{Panic disorder and IBS}

Panic disorder (PD) is a frequent psychiatric disorder, with a lifetime prevalence between $1.5 \%$ and $3.5 \%$.
Agoraphobia is present in $20,2 \%$ of patient affected by PD [36,37].

High comorbidity between IBS and PD has been identified in the literature $[3,17,38]$. The prevalence of IBS symptoms characteristics in patients with PD varies between 25 to $44 \%$, several symptoms being characteristic of the two disorders (nausea, diarrhea, abdominal discomfort) [39-42].

Recent studies tried to clarify the nature of the relationship between PD and IBS. One explanatory model is represented by the functional relationship between the central nervous system (CNS) and enteric nervous system (ENS). Much of the results of recent research suggest that the dysregulation of hypothalamic-pituitary-adrenal axis (disruption of the normal inhibitory feed-back) may represent a common pathway that may lead to stress vulnerability $[41,43,44]$. Patients with IBS and anxiety disorders present abnormally elevated basal cortisol levels and altered immune function (increased cytokines levels) [45-47].

There is evidence that the presence of avoidant behavior because of fear of IBS symptoms may be linked to a more severe form of agoraphobia, and the latter may also be associated with depression. The results of a recent study imply that presence of IBS may be related to anticipatory anxiety and agoraphobia in patients with PD [47,48].

\section{Generalised anxiety disorder and IBS}

Gastrointestinal-specific anxiety seems to perpetuate IBS symptoms through disruption of autonomic and pain facilitation, as well as cognitive mechanisms. Anticipatory worries and avoidance behavior are the main reason of affected functioning [49,50]. One study examined the relationship between IBS and GAD among IBS patients and healthy subjects and 32\% of subjects with IBS presented GAD symptoms as compared with other psychological manifestations [50]. According to this study, visceral sensitivity score (VSI) is the single powerful predictor of the severity of gastrointestinal-specific anxiety (GSA). Another study examined the prevalence, comorbidity and risks correlates of IBS in a general population and confirmed that there is a strong association between IBS and GAD, i.e., patients with comorbid IBS-GAD had more functional impairment and had more depressive symptoms [51].

Both diseases may benefit from treatment with antidepressants (selective serotonin reuptake inhibitors-SSRIs). Serotonin stimulates gastro-intestinal motility and visceral perception at CNS level by activating the serotonin receptor. SSRIs used for anxiety disorders and/or depression can improve the outcome of patients with IBS and associated psychiatric disorders, in special with constipationpredominant IBS form. However, is not entirely clear if the mechanism underlying IBS are linked to the drugs effects on mood [52]. 
Also, the results of a recent pilot study support the efficiency of duloxetine treatment in comorbid IBS and GAD. Patients reported significant reductions in IBS symptoms, as well as improvement in GAD [53].

\section{Post traumatic stress disorder and IBS}

A number of studies have consistently reported a relationship between history of various type of abuse and IBS. It is not clarified yet what is the connection between posttraumatic stress disorder (PTSD) and IBS. Much of the research had been focused on the role of sexual abuse as a risk factor to acquire IBS with most studies reporting an increased IBS risk [54,55].

Another study reported that $36 \%$ of patients with IBS have met lifetime diagnostic criteria of PTSD [56]. Other authors reported a substantially increased risk for IBS among female veterans diagnosed with PTSD or for military after deployment to war [57,58]. Indeed, one case study demonstrated that treating PTSD symptoms first may contribute to an improvement in IBS symptoms [59].

\section{Major depressive disorder and IBS}

One of the most diagnosed psychiatric disturbances in IBS patients is depression. There are many studies that evaluated the prevalence of anxiety and depression among patients with IBS seeking care in gastroenterology units but few studies have been done on IBS in psychiatric patients. An increased prevalence (27-47,3\%) of IBS in patients with major depression (onset or recurrent episode) was reported by several studies [60,61]. More recently, a cross-sectional study investigated the prevalence of IBS symptoms in patients diagnosed with major depressive disorder (MDD) [62]. The results demonstrated a higher prevalence of IBS symptoms in patients with depression compared with healthy subjects but patients with MDD in remission did not differ from healthy controls in reporting gastrointestinal symptoms.

Females with IBS have abnormal increased tryptophan degradation along the kynurenine pathway due to upregulation by proinflammatory cytokines. The rapid degradation of tryptophan depletes tryptophan and serotonin and produces toxic metabolites. This mechanisms could represent a possible biological basis for the high co-morbidity between IBS and depressive and anxiety disorders $[63,64]$.

\section{Bipolar disorders and IBS}

There are very few studies assessing the association between bipolar disorder and IBS. One community study found a lack of association between bipolar disorder and IBS [65]. Another case study reported no significant relationship between mood and IBS symptom severity [66].

\section{Schizophrenia and IBS}

Schizophrenia is a chronic disease associated with a highrisk of developing comorbid somatic illnesses. Somatic co-morbidities represent a major issue in patients with schizophrenia. The prevalence of IBS in schizophrenia patients was reported by Gupta and colleagues, to be $17 \%$ [67]. Another study reported a prevalence of $19 \%$ [68]. One of the main findings of this study was that patients with schizophrenia rarely complain about IBS symptoms, unless specifically asked. In patients with schizophrenia there may be significant barriers in obtaining adequate health care when comorbid disorders occur. These obstacles may be the result of patient psychotic symptomatology, stigma, and financial problems. It should be remembered that, under these circumstances, the actual prevalence of IBS symptoms may be higher, as these results are dependent upon individual reporting of symptoms.

\section{Alcohol abuse/dependence and IBS}

The findings relating alcohol abuse and IBS are contradictory. In population-based studies, alcohol abuse was not found to be associated with IBS. Moreover, the majority of patients with IBS tried to avoid certain food in order to reduce their symptoms, including alcohol

Table 1 Potential target genes associated with psychiatric diseases in IBS

\begin{tabular}{|c|c|c|c|c|c|}
\hline $\begin{array}{l}\text { Gene } \\
\text { symbol }\end{array}$ & Description & Gene function & $\begin{array}{l}\text { Gene expression } \\
\text { in IBS }\end{array}$ & Psychiatric diseases & Reference \\
\hline NGF & Nerve growth factor & $\begin{array}{l}\text { Pro-inflammatory mediator; } \\
\text { psychoneuroendocrine modulator }\end{array}$ & $\begin{array}{l}\text { Overexpression } \\
\text { (in rat model) }\end{array}$ & $\begin{array}{l}\text { Anxiety, chronic alcohol } \\
\text { consumption, depression }\end{array}$ & {$[71,72]$} \\
\hline BDNF & Brain-Derived Neurotrophic Factor & $\begin{array}{l}\text { Regulation of stress response and } \\
\text { in the biology of mood disorders }\end{array}$ & SNP & $\begin{array}{l}\text { Psychiatric IBS, schizophrenia, } \\
\text { mood disorders, PTSD }\end{array}$ & {$[73,74]$} \\
\hline \multirow[t]{2}{*}{ COMT } & Catechol & \multirow{2}{*}{$\begin{array}{l}\text { Degradative pathways of the } \\
\text { catecholamine transmitters; } \\
\text { metabolism of catechol drugs }\end{array}$} & \multirow[t]{2}{*}{ SNP } & \multirow{2}{*}{$\begin{array}{l}\text { Anxiety, panic disorder, and } \\
\text { cognitive performance }\end{array}$} & \multirow[t]{2}{*}[75,76]{} \\
\hline & O-Methyltransferase & & & & \\
\hline OPRM1 & Mu Opiate Receptor & $\begin{array}{l}\text { Principal target of endogenous } \\
\text { opioid peptides }\end{array}$ & SNP & $\begin{array}{l}\text { Pain sensitivity, opioid } \\
\text { dependence, and social sensitivity }\end{array}$ & {$[77,78]$} \\
\hline 5-HTTLPR & $\begin{array}{l}\text { 5-hydroxytryptamine transporter } \\
\text { gene-linked polymorphic region }\end{array}$ & Serotonin transporter & SNP & $\begin{array}{l}\text { Depression, anxiety, } \\
\text { rectal pain ratings }\end{array}$ & {$[79,80]$} \\
\hline
\end{tabular}


[69]. Still another study conducted in a psychiatric setting concluded that IBS is underdiagnosed in patients with alcohol abuse and alcohol dependence [61]. The findings of a recent study investigating the role of alcohol ingestion on gastrointestinal symptoms provided indication that it is the pattern of alcohol consumption may influence symptomatology in IBS patients [70].

\section{Genes involved in ibs and psychiatric comorbidities}

The pathogenesis of IBS associated with psychiatric comorbidities appears to have multifactorial aspects. Several factors appear to play a role in this process, such as psychological factors, genetic factors, chronic intestinal inflammation, and/or altered signaling in CNS and gut neuroendocrine system (NES) (Table 1). The IBS is not a "single gene" disease, many factors involved in IBS (e.g. individual vulnerability, psychosocial stressors) can be modulated by targeting these diseases at molecular level (interaction between genes and/or signaling pathway modulation in response to environment).

Neurotrophins like NGF (nerve growth factor) or Brainderived neurotrophic factor (BDNF) are involved, not only in somatic and visceral hypersensitivity, but also in neuronal survival, maturation and migration in the peripheral and central nervous system (CNS). Previous studies have reported a massive release of NGF in the peripheral circulation together with increased mRNA level in hypothalamus to integrate behavioral and neuroendocrine response following a psychosocial stress. Systemic administration of an anti-NGF antibody can prevent colonic hypersensibility and can be considered as a potential new therapeutic target $[71,72]$.

BDNF promote neural plasticity and plays an important role in the modulation of stress response and pathophysiology of mood disorders. Many studies were focused on the genetic polymorphisms associated with IBS. Yu and colleagues showed that the increased BDNF expression as compared with healthy controls in gut biopsies is associated with IBS [73]. On the other hand, BDNF Val66Met single nucleotide polymorphism (BDNF Val66Met SNP) was associated with decreased BDNF secretion from neurons and may lead to impairments in learning and altered susceptibility to stress [74].

Polymorphisms that affect many systems like serotonergic, adrenergic and opioidergic systems may also be involved in IBS pathophysiology. Adrenergic and opioidergic systems are involved in the modulation of motor and sensory function of gut and their polymorphism has been correlated with differential response to pain and with variation in alteration of gut motility [75-78].

Serotonin transporter gene (SERT) polymorphisms are associated with higher risk of depression in IBS patients. Thus individuals with a diminished function of serotonin transporters are more sensitive to gut signals in emotionregulating brain regions $[79,80]$.

\section{Conclusions}

A number of psychiatric comorbidities affect the patients with IBS. In particular, anxiety disorders and mood disorders occur with a significant greater frequency, indicating that the assessment or treatment of these comorbid conditions may influence the outcome of IBS. Although symptoms may improve with pharmacologic treatment, the residual manifestations of IBS may still impact the social and occupational functioning. Elucidating the molecular mechanisms of IBS with or without psychiatric comorbidities is crucial for elucidating the pathophysiology and for the identification of new therapheutical targets in IBS. A lot of data suggest the benefit of adjunctive psychological and genetical interventions but further investigation of such interventions is required.

\section{Competing interests}

The authors declare that they have no competing interests.

\section{Authors' contribution}

MFS, and DD and APW conducted the literature search and drafted the manuscript. AMB has made substantial contribution to conception and design of the manuscript. All authors read and approved the final manuscript.

\section{Author details}

${ }^{1}$ Department of Neurosciences, Iuliu Hatieganu University of Medicine and Pharmacy, Cluj-Napoca, Romania. ${ }^{2}$ Department of Psychiatry, University of Medicine, Rostock, Germany. ${ }^{3}$ 2nd Department of Medicine, luliu Hatieganu University of Medicine and Pharmacy, Cluj-Napoca, Romania. ${ }^{4}$ Department of Molecular Medicine, Iuliu Hatieganu University of Medicine and Pharmacy, Cluj-Napoca, Romania.

Received: 9 March 2014 Accepted: 15 June 2014

Published: 27 June 2014

\section{References}

1. Lea R, Hopkins V, Hastleton J, Houghton LA, Whorwell PJ: Diagnostic criteria for irritable bowel syndrome: utility and applicability in clinical practice. Digestion 2004, 70:210-213.

2. Stasi C, Bellini M, Bassotti G, Blandizzi C, Milani S: Serotonin receptors and their role in the pathophysiology and therapy of irritable bowel syndrome. Tech Coloproctol 2014, in press.

3. Canavan C, West J, Card T: The epidemiology of irritable bowel syndrome. Clin Epidemiol 2014, 6:71-80.

4. Doshi JA, Cai Q, Buono JL, Spalding WM, Sarocco P, Tan H, Carson RT: Economic burden of irritable bowel syndrome with constipation: a retrospective analysis of health care costs in a commercially insured population. J Manag Care Pharm 2014, 20:382-390.

5. Longstreth GF, Thompson WG, Chey WD, Houghton LA, Mearin F, Spiller RC: Functional bowel disorders. Gastroenterology 2006, 130:1480-1491.

6. Lovell RM, Ford AC: Global prevalence of and risk factors for irritable bowel syndrome: a meta-analysis. Clin Gastroenterol Hepatol 2012, 10:712-721.

7. Mulak A, Taché Y, Larauche M: Sex hormones in the modulation of irritable bowel syndrome. World J Gastroenterol 2014, 20:2433-2448.

8. Mayer EA, Tillisch $\mathrm{K}$ : The brain-gut axis in abdominal pain syndromes. Annu Rev Med 2011, 62:381-936.

9. Posserud I, Agerforz P, Ekman R, Bjornsson ES, Abrahamsson H, Simren M: Altered visceral perceptual and neuroendocrine response in patients with irritable bowel syndrome during mental stress. Gut 2004, 53:1102-1108.

10. Barbara G, Cremon C, Carini G, Bellacosa L, Zecchi L, De Giorgio R, Corinaldesi $R$, Stanghellini V: The immune system in irritable bowel syndrome. J Neurogastroenterol Motil 2011, 17:349-359. 
11. Kim SE, Chang L: Overlap between functional GI disorders and other functional syndromes: what are the underlying mechanisms? Neurogastroenetrol Motil 2012, 24:895-913.

12. Dinan TG, Quigley EM, Ahmed SM, Scully P, O'Brien S, O'Mahony L, O'Mahony S, Shanahan F, Keeling PW: Hypothalamic-pituitary-gut axis dysregulation in irritable bowel syndrome: plasma cytokines as a potential biomarker? Gastroenterology 2006, 130:304-311.

13. Fukudo S, Nomura T, Hongo M: Impact of corticotropin-releasing hormone on gastrointestinal motility and adrenocorticotropic hormone in normal controls and patients with irritable bowel syndrome. Gut 1998, 42:845-849.

14. Heitkemper M, Burr RL, Jarrett M, Hertig V, Lustyk MK, Bond EF: Evidence for autonomic nervous system imbalance in women with irritable bowel syndrome. Dig Dis Sci 1998, 43:2093-2098.

15. Whitehead WE, Palsson O, Jones KR: Systematic review of the comorbidity of irritable bowel syndrome with other disorders: what are the causes and implications? Gastroenterology 2002, 122:1140-1156.

16. Drossman DA, Toner BB, Whitehead WE, Diamant NE, Dalton CB, Duncan S, Emmott S, Proffitt V, Akman D, Frusciante K, Le T, Meyer K, Bradshaw B, Mikula K, Morris CB, Blackman CJ, Hu Y, Jia H, Li JZ, Koch GG, Bangdiwala SI: Cognitive-behavioral therapy versus education and desipramine versus placebo for moderate to severe functional bowel disorders. Gastroenterology 2003, 125:19-31.

17. Roy-Byrne P, Davidson K, Kessler R, Asmundson G, Goodwin R, Kubzansky L, Lydiard B, Jane Massie M, Wayne K, Laden S, Stein M: Anxiety disorders and comorbid medical illness. FOCUS 2008, 6:467-485.

18. Surdea-Blaga T, Băban A, Dumitrascu DL: Psychosocial determinants of irritable bowel syndrome. World J Gastroenterol 2012, 18:616-626.

19. Posserud I, Ersryd A, Simrén M: Functional findings in irritable bowel syndrome. World J Gastroenterol 2006, 12:2830-2838.

20. Piché M, Chen Jl, Roy M, Poitras P, Bouin M, Rainville P: Thicker posterior insula is associated with disease duration in women with irritable bowel syndrome (IBS) whereas thicker orbitofrontal cortex predicts reduced pain inhibition in both IBS patients and controls. J Pain 2013, 14:1217-1226.

21. Ellingson BM, Mayer E, Harris RJ, Ashe-McNally C, Naliboff BD, Labus JS, Tillisch K Diffusion tensor imaging detects microstructural reorganization in the brain associated with chronic irritable bowel syndrome. Pain 2013, 154:1528-1541.

22. Labus JS, Dinov ID, Jiang Z, Ashe-McNalley C, Zamanyan A, Shi Y, Hong JY, Gupta A, Tillisch K, Ebrat B, Hobel S, Gutman BA, Joshi S, Thompson PM, Toga AW, Mayer EA: Irritable bowel syndrome in female patients is associated with alterations in structural brain networks. Pain 2014, 155:137-149.

23. Blankstein U, Chen J, Diamant NE, Davis KD: Altered brain structure in irritable bowel syndrome: potential contributions of pre-existing and disease-driven factors. Gastroenterology 2010, 138:1783-1789.

24. Seminowicz DA, Labus JS, Bueller JA, Tillisch K, Naliboff BD, Bushnell MC Mayer EA: Regional gray matter density changes in brains of patients with irritable bowel syndrome. Gastroenterology 2010, 139:48-57.

25. Hong JY, Labus JS, Jiang Z, Ashe-Mcnalley C, Dinov I, Gupta A, Shi Y, Stains J, Heendeniya N, Smith SR, Tillisch K, Mayer EA: Regional neuroplastic brain changes in patients with chronic inflammatory and non-inflammatory visceral pain. PLoS One 2014, 9:e84564. doi:10.1371/journal.pone.0084564.

26. Berman SM, Naliboff B, Suyenobu B, Labus JS, Stains J, Ohning G, Kilpatrick L, Bueller J, Ruby K, Jarcho J, Mayer EA: Reduced brainstem inhibition during anticipated pelvic visceral pain correlates with enhanced brain response to the visceral stimulus in women with irritable bowel syndrome. I Neurosci 2008, 28:349-359.

27. Labus JS, Naliboff BD, Berman SM, Suyenobu B, Vianna EP, Tillisch K, Mayer EA Brain networks underlying perceptual habituation to repeated aversive visceral stimuli in patients with irritable bowel syndrome. Neuroimage 2009, 47:952-960

28. Labus JS, Naliboff BN, Fallon J, Berman SM, Suyenobu B, Bueller JA Mandelkern M, Mayer EA: Sex differences in brain activity during aversive visceral stimulation and its expectation in patients with chronic abdominal pain: a network analysis. Neuroimage 2008, 41:1032-1043.

29. Craggs JG, Price DD, Robinson ME: Enhancing the placebo response: fMR evidence of memory and semantic processing in placebo analgesia. J Pain 2014, 15:435-446.

30. Al-Chaer ED, Lawand NB, Westlund KN, Willis WD: Visceral nociceptive input into the ventral posterolateral nucleus of the thalamus: a new function for the dorsal column pathway. J Neurophysiol 1996, 76:2661-2674.

31. Arntz A, Claassens $L$ : The meaning of pain influences its experienced intensity. Pain 2004, 109:20-25
32. Tillisch K, Mayer EA, Labus JS: Quantitative meta-analysis identifies brain regions activated during rectal distension in irritable bowel syndrome. Gastroenterology 2011, 140:91-100.

33. Hobson AR, Aziz Q: Brain imaging and functional gastrointestinal disorders: has it helped our understanding? Gut 2004, 53:1198-1206

34. Aizawa E, Sato Y, Kochiyama T, Saito N, Izumiyama M, Morishita J, Kanazawa M, Shima K, Mushiake H, Hongo M, Fukudo S: Altered cognitive function of prefrontal cortex during error feedback in patients with irritable bowel syndrome, based on FMRI and dynamic causal modeling. Gastroenterology 2012, 143:1188-1198.

35. Coss-Adame E, Rao SS: Brain and gut interactions in irritable bowel syndrome: new paradigms and new understandings. Curr Gastroenterol Rep 2014, 16:379. doi:10.1007/s11894-014-0379-z.

36. Grant BF, Hasin DS, Stinson FS, Dawson DA, Goldstein RB, Smith S, Huang B, Saha TD: The epidemiology of DSM-IV panic disorder and agoraphobia in the United States: results from the national epidemiologic survey on alcohol and related conditions. J Clin Psychiatry 2006, 67:363-374.

37. Torres AR, Ferrão YA, Shavitt RG, Diniz JB, Costa DL, Rosário MC, Miguel EC, Fontenelle LF: Panic disorder and agoraphobia in OCD patients: clinical profile and possible treatment implications. Compr Psychiatry 2014, 55:588-597.

38. Gros DF, Antony MM, McCabe RE, Lydiard RB: A preliminary investigation of the effects of cognitive behavioral therapy for panic disorder on gastrointestinal distress in patients with comorbid panic disorder and irritable bowel syndrome. Depress Anxiety 2011, 28:1027-1033.

39. Kaplan DS, Masand PS, Gupta S: The relationship of irritable bowel syndrome (IBS) and panic disorder. Ann Clin Psychiatry 1996, 8:81-88.

40. Lydiard RB: Increased prevalence of functional gastrointestinal disorders in panic disorder: clinical and theoretical implications. CNS Spectr 2005, 10:899-908

41. Gros DF, Antony MM, McCabe RE, Swinson RP: Frequency and severity of the symptoms of irritable bowel syndrome across the anxiety disorders and depression. J Anxiety Disord 2009, 23:290-296.

42. Kumano H, Kaiya H, Yoshiuchi K, Yamanaka G, Sasaki T, Kuboki T: Comorbidity of irritable bowel syndrome, panic disorder, and agoraphobia in a Japanese representative sample. Am J Gastroenterol 2004, 99:370-376.

43. Elsenbruch S: Abdominal pain in Irritable bowel syndrome: a review of putative psychological, neural and neuro-immune mechanisms. Brain Behav Immun 2011, 25:386-394.

44. Goddard ER, Barth K, Lydiard RB: Disorders which frequently overlap with irritable bowel syndrome: can a shared neurobiology explain their association? Prim Psychiatr 2007, 14:69-73.

45. Vogelzangs N, Beekman AT, de Jonge P, Penninx BW: Anxiety disorders and inflammation in a large adult cohort. Trans/ Psychiatry 2013, 3:e249.

46. Rana SV, Sharma S, Sinha SK, Parsad KK, Malik A, Singh K: Pro-inflammatory and anti-inflammatory cytokine response in diarrhoea-predominant irritable bowel syndrome patients. Trop Gastroenterol 2012, 33:251-256.

47. Hoge EA, Brandstetter K, Moshier S, Pollack MH, Wong KK, Simon NM: Broad spectrum of cytokine abnormalities in panic disorder and posttraumatic stress disorder. Depress Anxiety 2009, 26:447-455.

48. Sugaya $\mathrm{N}$, Kaiya $\mathrm{H}$, Kumano $\mathrm{H}$, Nomura S: Relationship between subtypes of irritable bowel syndrome and severity of symptoms associated with panic disorder. Scand J Gastroenterol 2008, 43:675-681.

49. Sugaya N, Yoshida E, Yasuda S, Tochigi M, Takei K, Ohtani T, Otowa T, Minato T, Umekage T, Sakano Y, Chen J, Shimada H, Nomura S, Okazaki Y, Kaiya H, Tanii H, Sasaki T: Irritable bowel syndrome, its cognition, anxiety sensitivity, and anticipatory anxiety in panic disorder patients. Psychiatry Clin Neurosci 2013, 67:397-404.

50. Mayer EA, Craske MG, Naliboff BD: Depression, anxiety and the gastrointestinal system. J Clin Psychiatry 2001, 62:28-36.

51. Lee S, Wu J, Ma YL, Tsang A, Guo WJ, Sung J: Irritable bowel syndrome is strongly associated with generalized anxiety disorder: a community study. Aliment Pharmacol Ther 2009, 30:643-651

52. Vaiopoulou A, Karamanolis G, Psaltopoulou T, Karatzias G, Gazouli M: Molecular basis of the irritable bowel syndrome. World J Gastroenterol 2014, 20:376-383.

53. Kaplan AJ, Franzen MD, Nickell P, Ransom D, Lebovitz PJ: An open label trial of duloxetine in patients with irritable bowel syndrome and comorbid generalized anxiety disorder. Int J Psychiatry Clin Pract 2014, 18:11-15.

54. White DL, Savas LS, Daci K, Elserag R, Graham DP, Fitzgerald SJ, Smith SL, Tan G, El-Serag HB: Trauma history and risk of the irritable bowel syndrome in women veterans. Aliment Pharmacol Ther 2010, 32:551-561. 
55. Blanchard EB, Keefer L, Payne A, Turner SM, Galovski TE: Early abuse, psychiatric diagnoses and irritable bowel syndrome. Behav Res Ther 2002, 40:289-298

56. Irwin C, Falsetti SA, Lydiard RB, Ballenger JC, Brock CD, Brener W: Comorbidity of posttraumatic stress disorder and irritable bowel syndrome. J Clin Psychiatry 1996, 57:576-578.

57. Savas LS, White DL, Wieman M, Daci K, Fitzgerald S, Laday Smith S, Tan G, Graham DP, Cully JA, El-Serag HB: Irritable bowel syndrome and dyspepsia among women veterans: prevalence and association with psychological distress. Aliment Pharmacol Ther 2009, 29:115-125.

58. Goodwin L, Bourke JH, Forbes H, Hotopf M, Hull L, Jones N, Rona RJ, Wessely S, Fear NT: Irritable bowel syndrome in the UK military after deployment to Iraq: what are the risk factors? Soc Psychiatry Psychiatr Epidemiol 2013, 48:1755-1765.

59. Weaver TL, Nishith P, Resick PA: Prolonged exposure therapy and irritable bowel syndrome: a case study examining the impact of a trauma-focused treatment on a physical condition. Cogn Behav Pract 1998, 5:103-122.

60. Singh P, Agnihotri A, Pathak MK, Shirazi A, Tiwari RP, Sreenivas V, Sagar R, Makharia GK: Psychiatric, somatic and other functional gastrointestina disorders in patients with irritable bowel syndrome at a tertiary care center. J Neurogastroenterol Motil 2012, 18:324-331.

61. Masand PS, Sousou AJ, Gupta S, Kaplan DS: Irritable bowel syndrome (IBS) and alcohol abuse or dependence. Am J Drug Alcohol Abuse 1998, 24:513-521.

62. Karling P, Danielsson A, Adolfsson R, Norrback KF: No difference in symptoms of irritable bowel syndrome between healthy subjects and patients with recurrent depression in remission. Neurogastroenterol Motil 2007, 19:896-904

63. Fitzgerald P, Cassidy Eugene M, Clarke G, Scully P, Barry S, Quigley Eamonn MM, Dinan Timothy G: Tryptophan catabolism in females with irritable bowel syndrome: relationship to interferon gamma, severity of symptoms and psychiatric comorbidity. Neurogastroenterol Motil 2008, 20:1291-1297.

64. Sertbas Y, Belli H, Piskinpasa N, Ural C, Akbudak M, Sertbas M, Oncu F: Assesment of psychiatric symptoms and co-morbidities in patients with irritable bowel syndrome. W Indian Med J 2012, 61:544-548.

65. Mykletun A, Jacka F, Williams L, Pasco J, Henry M, Nicholson GC, Kotowicz MA Berk M: Prevalence of mood and anxiety disorder in self reported irritable bowel syndrome (IBS). An epidemiological population based study of women. BMC Gastroenterol 2010, 10:88

66. Crane C, Martin M, Johnston D, Goodwin GM: Does depression influence symptom severity in irritable bowel syndrome? Case study of a patient with irritable bowel syndrome and bipolar disorder. Psychosom Med 2003, 65:919-923.

67. Gupta S, Masand P, Kaplan D, Bhandary A, Hendricks S: The relationship between schizophrenia and irritable bowel syndrome (IBS). Schizophr Res 1997, 23:265-268.

68. Garakani A, Win T, Virk S, Gupta S, Kaplan D, Masand PS: Comorbidity of irritable bowel syndrome in psychiatric patients: a review. Am J Ther 2003, 10:61-67.

69. Halpert A, Halpert A, Dalton CB, Palsson O, Morris C, Hu Y, Bangdiwala S, Hankins J, Norton N, Drossman D: What patients know about irritable bowel syndrome (IBS) and what they would like to know. national survey on patient educational needs in ibs and development and validation of the patient educational needs questionnaire (PEQ). Am J Gastroenterol 2007, 102:1972-1982.

70. Reding KW, Cain KC, Jarrett ME, Eugenio MD, Heitkemper MM: Relationship between patterns of alcohol consumption and gastrointestinal symptoms among patients with irritable bowel syndrome. Am $J$ Gastroenterol 2013, 108:270-276.

71. Matricon J, Muller E, Accarie A, Meleine M, Etienne M, Voilley N, Busserolles J, Eschalier A, Lazdunski M, Bourdu S, Gelot A, Ardid D: Peripheral contribution of NGF and ASIC1a to colonic hypersensitivity in a rat model of irritable bowel syndrome. Neurogastroenterol Motil 2013, 25:e740-e754.

72. Berry A, Bindocci E, Alleva E: NGF, brain and behavioral plasticity. Neural Plast 2012, 2012:784040.

73. Yu YB, Zuo XL, Zhao QJ, Chen FX, Yang J, Dong YY, Wang P, Li YQ: Brain-derived neutrophic factor contributes to abdominal pain in irritable bowel syndrome. Gut 2012, 61:685-694

74. Frielingsdorf H, Bath KG, Soliman F, Difede J, Casey BJ, Lee FS: Variant brain-derived neurotrophic factor Val66Met endophenotypes: implications for posttraumatic stress disorder. Ann N Y Acad Sci 2011, 1208:150-157.
75. Saito Y, Larson J, Atkinson E, Ryu E, Elder AAE, Lee RM, Petersen GM: A candidate gene association study of functional "psychiatric" polymorphisms in irritable bowel syndrome. Gastroenterology 2010, 138:348.

76. Dickinson D, Elvevag B: Genes, cognition and brain through a COMT lens. Neuroscience 2009, 164:72-87.

77. Way BM, Lieberman MD: Is there a genetic contribution to cultural differences? Collectivism, individualism and genetic markers of social sensitivity. Soc Cogn Affect Neurosci 2010, 5:203-211.

78. Camilleri M, Busciglio I, Carlson P, McKinzie S, Burton D, Baxter K, Ryks M, Zinsmeister AR: Candidate genes and sensory functions in health and irritable bowel syndrome. Am J Physiol Gastrointest Liver Physiol 2008, 295:G219-G225.

79. Jarrett ME, Kohen R, Cain KC, Burr RL, Poppe A, Navaja GP, Heitkemper MM: Relationship of SERT polymorphisms to depressive and anxiety symptoms in irritable bowel syndrome. Biol Res Nurs 2007, 9:161-169.

80. Fukudo S, Kanazawa M, Mizuno T, Hamaguchi T, Kano M, Watanabe S, Sagami Y, Shoji T, Endo Y, Hongo M, Itoyama Y, Yanai K, Tashiro M, Aoki M: Impact of serotonin transporter gene polymorphism on brain activation by colorectal distention. Neuroimage 2009, 47:946-951.

doi:10.1186/2049-9256-2-4

Cite this article as: Fadgyas-Stanculete et al:: The relationship between irritable bowel syndrome and psychiatric disorders: from molecular changes to clinical manifestations. Journal of Molecular Psychiatry 2014 2:4.

\section{Submit your next manuscript to BioMed Central and take full advantage of:}

- Convenient online submission

- Thorough peer review

- No space constraints or color figure charges

- Immediate publication on acceptance

- Inclusion in PubMed, CAS, Scopus and Google Scholar

- Research which is freely available for redistribution 